\title{
LA RESPONSABILIDAD SOLIDARIA EN LA SUBCONTRATACIÓN LABORAL. ALGUNAS CONSIDERACIONES SOBRE SU NATURALEZA Y SUS EFECTOS
}

\author{
Claudio Palavecino Cáceres* \\ Universidad de Chile
}

\begin{abstract}
RESUMEN: El artículo 183-B del Código del Trabajo dispone que "la empresa principal será solidariamente responsable de las obligaciones laborales y previsionales de dar que afecten a los contratistas en favor de los trabajadores de éstos". Si bien esta referencia a una responsabilidad solidaria pareciera remitir directamente al concepto y estatuto de las obligaciones solidarias del Código Civil, tal remisión se ve dificultada por la posibilidad que abrió el legislador laboral de dividir la deuda entre los codeudores del empleador y por la necesidad de provocar un litisconsorcio pasivo con este para hacer exigible la responsabilidad de los codeudores. Se concluye que la solidaridad que establece el artículo 183-B del Código del Trabajo es sui generis y que, por ende, la determinación de sus efectos requiere ingentes esfuerzos dogmáticos.
\end{abstract}

Palabras clave: Subcontratación, responsabilidad solidaria, remision de normas del derecho común, beneficio de división, litisconsorcio pasivo, cosa juzgada.

ABSTRACT: Article 183-B of the Labor Code addresses that the "the main company is jointly liable for the labor and social security giving obligations that affect the contractors in relation to their employees". Athough this reference to a joint liability seems to refer directly to the concept and status of joint obligations of the Civil Code, such reference cannor be easily made because of the possibility opened by the labor legislator of dividing the debt between the co-debtors of the employer and also by the necessity for cause a passive "litisconsorcio" or joint litigation with him, to enforce with this the liability of the co-deptors. It is concluded that the solidarity addressed in Article 183-B of the Labor Code is sui generisand thus, the determination of its effects requires huge dogmatic efforts.

Key words: Outsourcing, solidary responsability, reference of the regulations of the common law, benefit of division, litisconsorcio pasivo, res iudicata.

\section{INTRODUCCION}

A través de la Ley $\mathrm{N}^{\circ} 20.123 / 2006$ se introdujo en el Libro Primero del Código del Trabajo (CT) un nuevo título (VII) denominado "Del trabajo en régimen de subcontratación y del trabajo en empresas de servicios transitorios". Con esta nueva regulación se quiso, entre otras cosas, intensificar la posición de garante del empresario que contrata con otro, obras o servicios, respecto de las obligaciones laborales y de seguridad social de sus contratistas y subcontratistas. En efecto, el artículo 183-B CT dispone que "la empresa principal será solidariamente responsable de las obligaciones laborales y

\footnotetext{
* Profesor de Derecho del Trabajo y la Seguridad Social, Facultad de Derecho de la Universidad de Chile. Contacto: cpalavec@derecho.uchile.cl
} 
previsionales de dar que afecten a los contratistas en favor de los trabajadores de estos"... añadiendo un poco más adelante que "en los mismos términos, el contratista será solidariamente responsable de las obligaciones que afecten a sus subcontratistas, a favor de los trabajadores de estos".

La norma citada delimita, además de los sujetos, el objeto y la extensión temporal de esta responsabilidad, pero sobre los efectos de la solidaridad misma nada dice, limitándose a recoger el nomen iuris del Derecho común. Si bien estas referencias normativas a una responsabilidad solidaria parecieran remitirnos, sin más, al concepto y estatuto de las obligaciones solidarias del Código Civil (CC), contenido en el título IX del Libro IV, artículos 1511 y siguientes, me propongo demostrar enseguida que tal remisión presenta severas dificultades ya que la solidaridad que establece el artículo 183-B CT es sui generis y que, por ende, la determinación de sus efectos requiere ingentes esfuerzos dogmáticos. En esta oportunidad limitaré mi contribución personal al estudio de los efectos entre los codeudores y el acreedor (relaciones externas), dejando para otra ocasión las relaciones de los codeudores entre sí (relaciones internas).

\section{2. ¿SOLIDARIDAD CON BENEFICIO DE DIVISIÓN?}

Conforme a la norma contenida en el inc. $2^{\circ}$ del art. $1511 \mathrm{CC}$, lo que hace que una obligación sea solidaria o insolidum es que, en virtud de la convención, del testamento o de la ley, pueda exigirse a cada uno de los deudores o por cada uno de los acreedores el total de la deuda. Se ha dicho que "[h] ay solidaridad pasiva cuando uno de los deudores puede ser constreñido a pagar la totalidad de la deuda, entendiéndose extinguida la relación obligatoria, una vez pagada, también, respecto de todos los demás deudores, los cuales internamente ajustarán cuentas con el que ejecutó la prestación"1. Como corolario de ello, en la solidaridad pasiva, el deudor solidario a quien se exige el total de la deuda no puede oponer al acreedor el beneficio de división (art. 1514 CC) "o sea, no puede pretender que se le cobre una parte proporcional de la deuda; está obligado al pago del total de ella"2. Pues bien, el legislador laboral se encarga de sembrar la primera duda sobre la aplicabilidad del estatuto original de la obligación solidaria, al limitar el alcance temporal de la responsabilidad del empresario principal. En efecto, el citado art. 183-B CT dispone que la responsabilidad solidaria "estará limitada al tiempo o período durante el cual el o los trabajadores prestaron servicios en régimen de subcontratación para la empresa principal". Por consiguiente, la empresa principal contra la cual se haga valer la responsabilidad "solidaria" no será, necesariamente, responsable por el total de la deuda contraída por el empleador-contratista con sus trabajadores. Esto solo ocurrirá cuando haya una coincidencia entre la duración de la participación del trabajador en la ejecución de la obra o servicio para la empresa principal y la extensión temporal del incumplimiento obligacional de su empleador. Así sucederá, por ejemplo,

\footnotetext{
${ }^{1}$ AlESSANDrI, Arturo; SOMARRIVA, Manuel; VODANOVIC, Antonio, Tratado de las obligaciones. Volumen I, De las obligaciones en general y sus diversas clases, segunda edición, Editorial Jurídica de Chile, Santiago, 2004, p. 121.

${ }^{2}$ Ibid., p. 137.
} 
cada vez que el trabajador sea contratado, precisamente, para la obra o servicio que debe ejecutar su empleador -el contratista- para la empresa principal y este incumpla obligaciones laborales y/o previsionales con el trabajador temporal. Pero, en otros casos, no habrá semejante sincronía y el responsable "solidario" lo será solo respecto de la parte alícuota de la deuda correspondiente al lapso en que el trabajador prestó servicios dentro de su ámbito organizacional, mientras que el empleador-contratista seguirá respondiendo por el total de la deuda. En tal caso, si el trabajador pretendiera reclamar íntegramente su crédito de la empresa principal codeudora, esta podría oponerle el beneficio de división de la deuda, quedando determinada su cuota sobre la misma en proporción al tiempo que el trabajador prestó servicios en régimen de subcontratación dentro su ámbito de organización y dirección ${ }^{3}$.

Consecuencia del límite temporal de la responsabilidad por créditos laborales y previsionales es que la peculiar "solidaridad" del art. 183-B CT opere solamente entre el empleador-contratista y la empresa principal (o, en su caso, entre el subcontratista-empleador y el contratista-mandante). En cambio, no habrá ya solidaridad, sino mera mancomunidad sobre las deudas laborales y previsionales entre las empresas principales que hubieren compartido, ya sea en forma sucesiva o simultánea, a un mismo contratista ${ }^{4}$. Por ende, si el contratista común incumple una obligación laboral o previsional con su trabajador, la deuda total se dividirá entre las empresas principales en proporción al tiempo que dicho trabajador laboró en cada una de ellas en régimen de subcontratación. Dado que la obligación es simplemente conjunta entre las empresas principales, cada deudor "es obligado solamente a su parte o cuota en la deuda" (art. 1511 , inc. $1^{\circ}, \mathrm{CC}$ ). Así, si un trabajador demanda solidariamente a varias empresas principales dentro de las cuales prestó sucesivamente servicios en régimen de subcontratación para un mismo empleador, aquellas podrán oponerle el beneficio de división, exigiendo que a cada una se la haga responsable nada más que de aquellas obligaciones devengadas mientras el trabajador permaneció en su respectivo ámbito organizativo. Asimismo ocurrirá cada vez que el trabajador demande solidariamente a dos o más empresas principales dentro de las cuales prestó simultáneamente servicios en régimen de subcontratación bajo subordinación de un mismo contratista: la deuda del empleador deberá fraccionarse en proporción al tiempo servido dentro de cada empresa principal y cada una responderá solamente de su respectiva cuota del monto total adeudado por el contratista común.

\footnotetext{
${ }^{3}$ Análogo límite temporal existe en el Uruguay, conforme al art. $8^{\circ}$ de la Ley $\mathrm{N}^{\circ} 18.251$ (de enero de 2008), según el cual, la responsabilidad de la empresa principal queda exclusivamente limitada “...a las obligaciones devengadas durante el periodo de subcontratación, intermediación o suministro de mano de obra por el personal comprendido en cualquiera de las modalidades de contratación referidas". Al respecto, Garmendia y Gauthier concluyen que la responsabilidad solidaria pasiva de su país "por imperio del propio sistema legal, contiene en sí mismo un mecanismo de división o fraccionamiento de la deuda entre los diversos deudores, el que toma como base a tales efectos, el tiempo real en que efectivamente se desempeñaron para cada uno de ellos los dependientes de la empresa contratada". GARMENDIA, M. y GAUTHIER, G., Tercerizaciones. Nuevo régimen legal. Leyes $N^{\circ} 18.099$ y $N^{\circ} 18.251$, Fundación de Cultura Universitaria, Montevideo, 2008, p. 142.

${ }^{4}$ Lo mismo sucede en la legislación del Uruguay, donde "la solidaridad pasiva solo se traba entre cada una de las empresas principales y la empresa contratada (subcontratista, intermediaria o suministradora de mano de obra), pero nunca se generarán lazos de responsabilidad solidaria 'cruzados' entre las diversas empresas principales a las que la subcontratista, intermediaria o suministradora de mano de obra hubiera brindado servicios", en ibid., pp. 142-143.
} 
Claudio Palavecino Cáceres / La responsabilidad solidaria en la subcontratación laboral...

\subsection{NECESIDAD DE LITISCONSORCIO PASIVO CON EL EMPLEADOR PARA RECLAMAR LA RESPONSABILIDAD DE LA EMPRESA PRINCIPAL}

Otro rasgo distintivo de la obligación solidaria en el Derecho común es la inexigibilidad de litisconsorcio pasivo para demandar su cumplimiento. El art. 1514 CC prescribe en tal sentido que el "acreedor podrá dirigirse contra todos los deudores solidarios conjuntamente, o contra cualquiera de ellos a su arbitrio....". Como dice Peñailillo "el acreedor elige" 5 . Por su parte, el inc. $4^{\circ}$ del art. 183-B CT, dispone que "el trabajador, al entablar la demanda en contra de su empleador directo, podrá hacerlo en contra de todos aquellos que puedan responder de sus derechos...". Esta norma ofrece al trabajador la posibilidad de generar un litisconsorcio pasivo entre su empleador y la empresa (o empresas) dentro de la $(s)$ cual(es) hubiere prestado servicios en régimen de subcontratación. Dado que los términos del citado inc. $4^{\circ}$ del art. 183-B CT no son imperativos (el trabajador [...] podrá...), la norma resultaría, a primera vista, concordante con la contenida en el 1514 CC y, por ende, tampoco la ley laboral impondría un litisconsorcio pasivo para reclamar la responsabilidad solidaria; entonces, el trabajador podría elegir entre provocar el litisconsorcio pasivo o demandar únicamente a su empleador o bien $-\mathrm{y}$ esta es la hipótesis más conflictiva- descartar al empleador y demandar directa y únicamente a la empresa principal. De aceptarse lo cual se seguiría que el trabajador del contratista tendría una acción autónoma contra la empresa principal para reclamar judicialmente el cumplimiento de sus derechos laborales y previsionales ${ }^{6}$. Así lo entiende Prado, para quien "es posible interpretar el artículo 183-B, inciso cuarto, en forma armónica con el artículo 1514 del Código Civil, por que se permitiría una demanda del trabajador únicamente contra la principal, sin necesidad de ejercer la acción respectiva también contra el contratista..."7.

Sin necesidad de recurrir a consideraciones utilitaristas unidireccionales, de escasa o nula sustancia jurídica, quien quisiera sostener esta interpretación podría encontrar apoyo en la vieja tesis de la civilística francesa del "mandato tácito y recíproco" que existiría entre los deudores de la obligación solidaria ${ }^{8}$. $\mathrm{O}$ bien, dado que estamos ante una solidaridad de fuente legal, donde la idea del mandato entre los codeudores es menos verosímil que en la solidaridad convencional, se podría recurrir a la tesis, más actual, de la representación mutua de los deudores frente al acreedor impuesta de oficio por la ley ${ }^{9}$.

Si bien la lectura planteada es admisible, prima facie, diversas consideraciones -especialmente los inconvenientes que suscita al llevarla al campo procesal- ${ }^{10}$ aconsejan

\footnotetext{
5 Peñallillo, Daniel, Obligaciones. Teoría general y clasificaciones. La resolución por incumplimiento, Editorial Jurídica de Chile, Santiago, 2003, reimpresión de 2008, p. 274.

${ }^{6}$ Así lo entendimos en un primer momento. PALAVECINO, Claudio, Subcontratación. Régimen juridico del trabajo subcontratado y del suministro de personal, Editorial Jurídica de Chile, Santiago, 2006, passim.

${ }^{7}$ PRADO, P., La subcontratación y el suministro en el Derecho civil, Legal Publishing, Santiago, 2009, p. 69

8 Vid. Somarriva, Manuel, Tratado de las cauciones, Editorial Nascimento, Santiago, 1943, pp. 50 y ss. Con todo, debe tenerse presente la polémica nacional en torno a las notas marginales de don Andrés Bello al Proyecto de 1841-1845 en relación a la teoría francesa del mandato entre los codeudores, particularmente en cuanto señala que "el proyecto se separa aquí del Código francés y sigue al Derecho Romano".

9 Vid. Peñailillo, Daniel, op. cit., p. 265. Alessandri, Arturo; Somarriva, Manuel; Vodanovic, Antonio, op. cit., p. 136.

${ }^{10}$ Alessandri, Arturo; Somarriva, Manuel; VodanoviC, Antonio, op. cit., p. 136.
} 
revisarla y separarse en este punto del estatuto original de la obligación solidaria, contenido en el CC.

No debe perderse de vista que el art. 183-B CT desplaza la responsabilidad por obligaciones laborales y de la seguridad social que afectan al empleador hacia terceros ajenos al contrato de trabajo. Este desplazamiento de la responsabilidad contractual surge directa y objetivamente de la ley, sin que la voluntad de estos terceros juegue papel alguno para determinar su atribución ${ }^{11}$. La ley altera, de esta manera, el efecto relativo del contrato de trabajo.

Pero lo cierto es que el empresario principal no es empleador de los trabajadores del contratista; tampoco el contratista lo es de los trabajadores del subcontratista. El propio legislador laboral parece comprenderlo así, puesto que no estableció ningún tipo de ficción en el sentido de considerar a la empresa principal coempleadora. Antes, al contrario, el art. $183-\mathrm{B}$, inc. $4^{\circ}$, CT distingue nítidamente entre el empleador directo del trabajador y todos aquellos que puedan responder de sus derechos... No existe, por tanto, en el plano formal, ni menos todavía en el plano material ${ }^{12}$, una situación de igualdad entre los deudores "solidarios" frente al acreedor común. De un lado está el empleador directo o, mejor dicho, empleador "a secas", que es responsable principal, puesto que acordó con el trabajador los términos del contrato que ahora incumple y, de otro, la persona natural o jurídica dueña de la obra, empresa o faena, que no concurrió con su voluntad al contrato de trabajo pero que, sin embargo, es responsable de sus efectos frente a un trabajador ajeno por pura imposición legal. No habiendo sido investida la empresa principal de la condición de coempleadora, no puede sostenerse tampoco la ficción de un mandato tácito y recíproco entre los deudores solidarios para el pago de las obligaciones insolidum, ni siquiera la de una representación recíproca entre ellos, de

\footnotetext{
11 Se ha intentado construir una teoría de responsabilidad subjetiva para explicar la solidaridad, la cual parte del supuesto que la responsabilidad basal del sistema establecido por el CT es subsidiaria y que la solidaridad sería una intensificación de la responsabilidad que operaría como una sanción al empresario principal que incurre en culpa in eligendo vel vigilando respecto de sus contratistas. Así, Lizama y Ugarte, quienes plantean que la ley establece "un eventual agravamiento de la responsabilidad subsidiaria de la empresa principal, pero no por un hecho del contratista [...] sino por un hecho suyo: debe responder solidariamente por no haber ejercido los derechos de control que la ley le otorga...", en: LIZAMA PORTAL, Luis y UGARTE, José Luis, Subcontratación y suministro de trabajadores, LexisNexis, Santiago, 2007, p. 59. En igual sentido se pronuncia Prado, "la empresa principal responderá solidariamente en la medida que no haga valer sus derechos de información y retención, por el contrario, si los ejercita responderá subsidiariamente, tal como lo venía haciendo bajo la vigencia de los artículo 64 y 64 bis”, en: PRADO, P., op. cit., p. 45 . Desde luego tal construcción no se corresponde con la intención del legislador que fue, precisamente, sustituir el régimen de responsabilidad subsidiaria por la solidaridad y en que la "rebaja" de responsabiliad opera como premio al ejercicio oportuno de los derechos de información y retención. No se ve cómo se podría imponer sanciones por el "no ejercicio" de derechos, cuando lo que define un derecho subjetivo es precisamente su disponibilidad y la inocuidad de la decisión de ejercerlo o no. Para justificar su tesis los autores pretenden que donde el legislador dijo "derecho" quiso decir "carga". Lo admite Prado cuando dice que "... aun cuando entendemos la conveniencia de la denominación "derecho' utilizada por el legislador, es fácil percatarse que tiene una especial característica, que incluso nos evoca a la 'carga'...”, en: PRADO, P., op cit., p. 46.

${ }^{12}$ Como observa autorizada doctrina argentina, "la empresa que contrata los servicios de otra, por regla general desconoce las características del trabajador afectado a las tareas encomendadas, así como también la modalidad salarial, el horario, la operatoria impuesta para el logro de los fines empresarios, y demás condiciones de contratación, resultando totalmente ajeno a los devenires propios del vínculo, tales como ascensos, traslados, recategorizaciones, etc.”, en: RAINOLTER, M. y GARCla Vior, A., Solidaridad laboral en la tercerización, Astrea, Buenos Aires, 2008, p. 256.
} 
manera tal que, emplazado que fuere cualquiera de los codeudores, pudiera entenderse igualmente emplazados a todos los demás.

Por otra parte, es un presupuesto necesario o condición sine qua non para que proceda la atribución de la responsabilidad del art. 183-B CT determinar primeramente la responsabilidad contractual, vale decir, la existencia de obligaciones incumplidas entre trabajador y empleador. En tal sentido, la responsabilidad que el art. 183-B CT impone a la empresa principal no puede ser sino accesoria a la responsabilidad contractual del empleador. Por tanto, no parece razonable que se condene al deudor accesorio, si no se condena al deudor principal. Como señaló una sentencia en la Argentina, país donde doctrina y jurisprudencia han discutido intensamente el punto:

"la demanda contra el deudor [principal] y la obtención de un pronunciamiento expreso acerca de la existencia de una obligación concreta en cabeza de aquél, son imprescindibles, por necesidad lógica, para hacer efectiva la responsabilidad de quienes, de no mediar las disposiciones legales en cuya virtud se los demanda, serían perfectos terceros. Los pretensores deben demostrar, por una parte, la existencia y exigibilidad de sus créditos respecto del demandado principal y, por otra, alegar y probar los presupuestos de operatividad de las normas invocadas para traer a juicio a esos terceros" 13 .

Como observan los argentinos Rainolter y García-Vior, tampoco haría aconsejable la acción directa contra el empresario principal la garantía del debido proceso, puesto que el empresario principal carecería de "elementos de juicio para evaluar la demanda que se le formula, quedando supeditada su actuación a lo que en definitiva pudiera plantearse mediante una citación de terceros o una declaración testimonial, lo que crea un álea gravosamente atentatoria del derecho de defensa de quien, cabe puntualizarlo, resulta ser un perfecto extraño en el vínculo obligacional que se le opone"14.

Se ha contradicho esta objeción, bajo el argumento que, de no demandar al empleador, el perjuicio es para el propio trabajador que "tendrá una doble carga probatoria, ya que previo a resolver si hay solidaridad, se deberá acreditar la existencia del crédito laboral a su favor"15. Reconociendo como cierto esto último, no me parece, sin embargo, que la mayor exigencia probatoria para el trabajador cubra satisfactoriamente el déficit garantístico para la empresa principal, considerando, sobre todo, que no existe el mismo grado de proximidad al material probatorio del trabajador respecto de sus créditos, entre quien es o ha sido su empleador (y por ende ha tenido acceso directo a los futuros medios de prueba durante el curso de la relación laboral), y el tercero, en principio ajeno al contrato, a quien la ley convierte en codeudor, pues este último, en ausencia del empleador, deberá ejercer sus derechos de contradicción e impugnación sobre la prueba aportada por el trabajador ajeno, casi siempre sobre la base de conjeturas o sospechas.

\footnotetext{
${ }^{13}$ Citada por Rainolter, M. y Garcta VIOR, A., ibid., p. 250.

14 RAINOLTER, M. y GARClA VIOR, A., op. cit., p. 256.

15 Hierrezuelo, R. y NúÑEZ, P., Responsabilidad solidaria en el contrato de trabajo, segunda edición, Hammurabi, Buenos Aires, 2008, p. 78.
} 
Bajo la luz de los razonamientos expuestos, una lectura mayormente razonada de la norma contenida en el inc. $4^{\circ}$ del art. 183-B CT, nos obliga a concluir que, en efecto, [e]1 trabajador, al entablar la demanda en contra de su empleador directo, podrá..., si así lo quiere, hacer efectiva la responsabilidad de la empresa principal (solidaria y/o subsidiaria), en cuyo caso será obligatorio que dirija su demanda conjuntamente contra el contratista o subcontratista (empleador directo) y contra todos aquellos que puedan responder de sus derechos ${ }^{16}$. En cambio, nada impide que el trabajador demande solamente contra su empleador directo, en cuyo caso la ley no le exige provocar un litisconsorcio pasivo. La redacción facultativa del precepto se refiere, pues, únicamente, a esta última posibilidad ${ }^{17}$.

\section{LA ACCIÓN DE COSA JUZGADA DEL TRABAJADOR}

En la hipótesis últimamente formulada, en que el trabajador no provoca un litisconsorcio pasivo entre su empleador y los responsables vicarios, surge la pregunta si podría, una vez ejecutoriada la sentencia que condena al empleador, iniciar la ejecución en contra de este y de todos aquellos que puedan responder de sus derechos. Planteando lo mismo de otro modo: ¿podría el trabajador ejercitar la acción de cosa juzgada contra la empresa principal no emplazada en el juicio declarativo ganado al empleador? Somarriva enseñaba que:

“[a]plicando la doctrina del mandato tácito y recíproco que liga a los deudores, es evidente que la sentencia dictada contra uno de ellos tiene que producir efecto de cosa juzgada con respecto a los otros, ya que existiría identidad legal de persona en ambos juicios. Refuerza esta misma conclusión el hecho de que el artículo 2.354 señale la cosa juzgada como una excepción real, que en consecuencia pueden oponer todos y cada uno de los deudores solidarios. Y si ellos pueden hacer uso de la cosa juzgada para defenderse cuando les es favorable, es lógico que también pueda invocarse en su contra cuando los condene"18. Aunque de inmediato el autor prevenga que "[n]aturalmente, la cosa juzgada debe entenderse [...] sin perjuicio de las excepciones personales que pueden oponer los otros deudores

\footnotetext{
${ }^{16}$ Aunque finalmente lo descarte, Prado admite, prima facie, "que es posible interpretar esta disposición entendiendo que el trabajador tiene dos opciones: o demanda solo a su empleador directo (la contratista); o bien, para hacer efectiva la responsabilidad solidaria de la empresa principal necesariamente debe demandarla en forma conjunta con la contratista", en: PRADO, P., op. cit., p. 68.

${ }^{17}$ Aleccionador sobre esta materia debiera resultarnos el caso uruguayo. Rosembaun y Castello dan cuenta de las "consecuencias negativas y disfuncionales" que podía provocar la aplicación lisa y llana del régimen de solidaridad previsto en la Ley $\mathrm{N}^{\circ} 18.099$ de enero de 2007, que no exigía litisconsorcio pasivo con el empleador para demandar la responsabilidad solidaria o subsidiaria contra la empresa principal. Un año después (enero de 2008), la Ley $\mathrm{N}^{\circ} 18.251$ corrigió esta omisión, al disponer, en su art. 10, que en los procesos en los que se invoquen las responsabilidades subsidiaria o solidaria, deberán ser emplazadas conjuntamente todas las personas contra las cuales se pretenda exigir el cumplimiento de las obligaciones. Para los autores citados "[e]llo se traduce en que si el trabajador desea reclamar no solamente contra su empleador directo, sino también contra aquel que entiende mantiene un vínculo de intermediación, subcontratación o suministro de mano de obra, deberá incluirlo en su demanda y emplazarlo conjuntamente con su patrono", en: ROSEMBAUM, J. y CASTEllo, A., Subcontratación e intermediación laboral. Estudio de las leyes 18.099 y 18.251, Fundación de Cultura Universitaria, Montevideo, 2008, p. 165.

18 Somarriva, Manuel, op. cit., p. 56.
} 
Claudio Palavecino Cáceres / La responsabilidad solidaria en la subcontratación laboral...

y del derecho para invocar la colusión que pueda haber existido entre el acreedor y el deudor vencido" 19 .

A esta argumentación le son oponibles, y todavía con mayor intensidad, las consideraciones ya esgrimidas para fundamentar la necesidad de litisconsorcio pasivo de los responsables solidarios con el empleador en el juicio declarativo. Coincidimos con Peñailillo en que "para que proceda siquiera discutir la extensión de la cosa juzgada a otros deudores solidarios, debe estar fehacientemente establecida la existencia de tales otros" ${ }^{20}$. Añade este autor que:

"en la aplicación de la acción de cosa juzgada [...] queda patente que, para que sea posible, es necesario que el otro deudor (a quien se pretende ejecutar con el primer fallo) aparezca individualizado en la sentencia declarativa y, más aún, será necesario que en la sentencia este otro deudor a quien se quiere ahora ejecutar aparezca también como condenado, aparezca declarado deudor, lo cual es muy difícil si no ha sido litigante" 21 .

Menos aún podría el trabajador, en la ejecución que siguiere contra uno de los deudores, embargar bienes de los otros. Somarriva recuerda que "[n]uestra jurisprudencia ha tenido ocasión de aplicar este principio en más de una oportunidad con relación al caso en que un bien que pertenece en común a todos los co-deudores solidarios sea embargado en su totalidad en la ejecución seguida contra uno solo de ellos"22.

Con todo, debe tenerse presente la enigmática norma sobre ejecución laboral contenida en el inciso final del art. $466 \mathrm{CT}$, conforme a la cual, una vez practicada la liquidación del crédito esta deberá ser notificada por carta certificada a las partes, pero "[e]n caso que la ejecución haya quedado a cargo de un tercero, la notificación deberá practicarse a este en forma personal". ¿Quién es este "tercero" sobre el cual pudiera recaer la ejecución? Una lectura apresurada podría conducir a la idea que el legislador se está refiriendo a un sujeto ajeno al proceso declarativo... por ejemplo, a la empresa principal que no fue convocada al juicio declarativo. Bastaría, entonces, con notificar personalmente la liquidación del crédito a la empresa principal para poder hacer valer, recién aquí, in extremis, su responsabilidad solidaria, sin necesidad de emplazarla en el juicio declarativo. Por todas las razones ya expuestas no podemos admitir como válida semejante conclusión.

¿Cómo dar sentido, entonces, a la citada norma del inciso final del art. 466 CT? En este punto resulta oportuno y útil recordar lo ya señalado supra, en el sentido que la empresa principal, aun cuando haya sido demandada y válidamente emplazada en el juicio contra el contratista empleador, seguirá siendo "tercero", no ya desde el punto de vista procesal, evidentemente, toda vez que ha sido parte en el juicio declarativo, pero sí desde el punto de vista contractual, puesto que no es ni será parte jamás del contrato de trabajo

\footnotetext{
19 Ibid.

${ }^{20}$ PeŃailillo, Daniel, op. cit., p. 277.

21 Ibid., p. 279.

22 SOMARRIVA, Manuel, op. cit., pp. 54-55.
} 
celebrado entre el contratista y el trabajador. Recién cuando quede establecido de manera indubitada la existencia del crédito a favor del trabajador y la existencia de todos aquellos que puedan responder por sus derechos, lo cual ocurrirá cuando la sentencia que condena solidariamente al contratista empleador y a la empresa principal quede ejecutoriada, podrá entonces el trabajador decidir contra quién dirige la acción ejecutiva, si contra ambos o únicamente contra la empresa principal. En este último caso se estará, efectivamente, ante un "tercero" (alguien que no ha sido parte del contrato de trabajo) a cuyo cargo ha quedado la ejecución y será preciso notificarle personalmente la liquidación del crédito junto con el requerimiento de pago, en cumplimiento de lo ordenado por el art. 466 inciso final CT.

\section{EXCEPCIONES QUE PUEDE OPONER LA EMPRESA PRINCIPAL}

\subsection{EN EL JUICIO DECLARATIVO}

Provocado que fuere el litisconsorcio pasivo entre el contratista-empleador y la empresa principal, esta podrá controvertir tanto los presupuestos de la responsabilidad que se le imputa, vale decir, negar su condición de codeudora del empleador directo, como el monto, e incluso la existencia misma del crédito que reclama el trabajador.

La inoponibilidad de fondo se sustentará en la ausencia de alguno de los presupuestos que, conforme al art. 183-A CT, configuran el trabajo en régimen de subcontratación, tales como la inexistencia de relación negocial entre la compañía demandada y el empleador; la existencia de un contrato entre la compañía demandada y el contratista, pero que no tiene por objeto la ejecución de una obra o servicio, sino un simple dare; obras o los servicios que se ejecutan o prestan de manera discontinua o esporádica por el contratista; obras o servicios que se ejecutan o prestan de manera permanente por el contratista, pero fuera de los espacios físicos controlados por la empresa principal; obras o los servicios que se ejecutan o prestan de manera permanente por el contratista en la empresa principal, en los cuales no tuvo participación alguna el trabajador que pretende reclamar de esta última responsabilidad solidaria respecto de sus créditos insolutos.

Como quedó dicho, la empresa principal podrá también atacar la existencia y monto del crédito reclamado por el trabajador oponiendo todas las excepciones que resulten de la naturaleza de la obligación, y además todas las personales suyas (art. 1520 inc. $\left.1^{\circ} \mathrm{CC}\right)^{23}$.

En tal sentido no le son oponibles a la empresa principal el allanamiento total o parcial del contratista respecto de la pretensión del trabajador, ni la transacción a la que empleador y trabajador pudieran llegar producto del llamado a conciliación.

\subsection{EN EL JUICIO EJECUTIVO}

Conforme con lo preceptuado en el art. 470 CT, la parte ejecutada solo podrá oponer, dentro del plazo de cinco días contados desde la notificación de la liquidación del crédito y el requerimiento de pago, acompañando antecedentes escritos de debida

\footnotetext{
23 Vid., en detalle, AleSSANDri, Arturo; SOMARriva, Manuel; Vodanovic, Antonio, op. cit., pp. 146 y ss. SOMARRIVA, Manuel, op. cit., pp. 69 y ss.
} 
Claudio Palavecino Cáceres / La responsabilidad solidaria en la subcontratación laboral...

consistencia, alguna de las siguientes excepciones: pago de la deuda, remisión, novación y transacción.

En Chile, incluso respecto de la solidaridad civil, se da por descontado que "los derechos del acreedor sólo pueden hacerse efectivos sobre los bienes de los deudores condenados judicialmente; pero no sobre los de aquellos que no han sido requeridos para el pago, ya que éstos no han sido oídos y pueden tener excepciones que los primeros no tenían o no esgrimieron" 24 .

\section{CONCLUSIONES}

Acaso no exista otra disciplina jurídica en Chile, distinta del Derecho del trabajo, en que legislador, jurisprudencia y dogmática hayan contribuido de modo más denodado a la. vulgarización de los conceptos del Derecho común ${ }^{25}$. Un método recurrente, mediante el cual el legislador chileno improvisa soluciones a los complejos problemas que plantean las relaciones laborales, consiste en tomar prestadas instituciones del Derecho civil, ignorando su contenido e interpretación, decantados tras siglos -y a veces milenios- de profunda y rigurosa reflexión jurídica, para aplicarlas irreflexivamente a situaciones distintas de aquellas para las cuales cada figura fuera originalmente concebida. Unas veces el legislador laboral se limita a copiar el nomen iuris, obviando por completo la determinación de los contenidos; otras, en cambio, ofrece algunos elementos sustantivos para esa determinación, pero que resultan contradictorios con la configuración afianzada de la institución en su rama de origen. No puede extrañar que estas técnicas improvisadas de extrapolación e hibridación casi siempre fracasen. A poco andar se percibe entre los operadores jurídicos la imposibilidad de aplicar el contenido normativo y la elaboración dogmática de las instituciones conforme a sus fuentes originales y la necesidad de abandonar su estatuto tradicional, con graves efectos sobre la seguridad jurídica ${ }^{26}$. Las lagunas que negligentemente deja el legislador, son llenadas por cuerda separada, y no pocas veces con resultados contradictorios, por la administración y la judicatura laborales, usando, cada cual a su modo, el tosco aparataje conceptual de la disciplina, los "principios" y los demás sortilegios de una

\footnotetext{
${ }^{24}$ AlesSandri, Arturo; Somarriva, Manuel; Vodanovic, Antonio, op. cit., p. 138.

25 ¡Y no solo del Derecho común! Desde el ámbito del Derecho constitucional, Ferrada ha llamado la atención, recientemente, sobre el entusiasmo con que "la doctrina laboral más progresista" ha recibido el procedimiento de tutela de los derechos fundamentales, "declarándose abiertamente partidaria de esta nueva manifestación de eficacia directa e inmediata de las normas constitucionales y, derivando de lo mismo, la eficacia horizontal de los derechos fundamentales. Ello ha impedido una reflexión más serena por esta misma doctrina, confundiendo conceptos básicos de la teoría constitucional, desnaturalizando algunos conceptos elementales de derecho constitucional y otorgando una aplicación desmesurada y peligrosa a la doctrina germana de la drittwirkung". Vid. FERRADA, J.C.: "Abriendo camino en la tutela de derechos fundamentales en materia laboral: buenas intenciones, malos instrumentos (Juzgado de Letras del Trabajo de Copiapó), en: Revista de Derecho, vol. XXI - No 2 -, Santiago, diciembre 2008, pp. 251-271.

26 Asi ha ocurrido con la científicamente indescifrable "nulidad" de despido por deuda previsional, mejor conocida como "ley Bustos" (19.631/1999), un galimatías tal que ha provocado en dos lustros la más disparatada jurisprudencia y una ley interpretativa (la 20.194/2007) que en lugar de aclarar las cosas, las obscurece. Vid. PAlaveCINO, Claudio, "El despido nulo por deuda previsional: un esperpento jurídico", en Ius et Praxis, Año 8, No 2, Talca, 2002, pp. 557573. Más reciente, LANATA, Gabriela, Contrato individual del trabajo, tercera edición, LegalPublishing, Santiago, 2009, pp. 330-339.
} 
doctrina que, sin reparar en los medios, persigue a toda costa una quimera -un objeto de deseo inalcanzable, diría Lacan-, me refiero al sueño confuso de la justicia social.

Un ejemplo más de vulgarización por laboralización es la tentativa del legislador chileno de intensificar la responsabilidad de la empresa principal sobre los créditos laborales y previsionales de los trabajadores del contratista, transmutando -o más bien dicho creyendo trasmutar- dicha responsabilidad de subsidiaria en solidaria. A nadie puede extrañar entonces que el Derecho del trabajo chileno sea el reino de lo sui generis.

\section{BIBLIOGRAFÍA}

Alessandri, Arturo; Somarriva, Manuel; Vodanovic, Antonio, Tratado de las obligaciones. Volumen I, De las obligaciones en general y sus diversas clases, segunda edición, Editorial Jurídica de Chile, Santiago, 2004.

BARCIA, Rodrigo, Lecciones de Derecho civil chileno. De la teoría de las obligaciones. Tomo III, Editorial Jurídica de Chile, Santiago, 2008.

FERRADA, J.C.: "Abriendo camino en la tutela de derechos fundamentales en materia laboral: buenas intenciones, malos instrumentos (Juzgado de Letras del Trabajo de Copiapó), en: Revista de Derecho, vol. XXI -No 2-, Santiago, diciembre 2008, pp. 251-271.

Garmendia, M. y GauthieR, G., Tercerizaciones. Nuevo régimen legal. Leyes $N^{\circ} 18.099$ y $N^{\circ} 18.251$, Fundación de Cultura Universitaria, Montevideo, 2008.

HIERREZUELO, R. y NÚNẼE, P., Responsabilidad solidaria en el contrato de trabajo, segunda edición, Hammurabi, Buenos Aires, 2008.

Lanata, Gabriela, Contrato individual del trabajo, tercera edición, Legal Publishing, Santiago, 2009.

LIZAMA PORTAL, Luis y UGARTE, José Luis, Subcontratación y suministro de trabajadores, LexisNexis, Santiago, 2007.

Millón, P., La responsabilidad subsidiaria en la legislación laboral, ConoSur, Santiago de Chile, 2001.

PALAVECINO, Claudio, "El despido nulo por deuda previsional: un esperpento jurídico", en Ius et Praxis, Año 8, No 2, Talca, 2002, pp. 557-573.

PALAVECINO, Claudio, Subcontratación. Régimen jurídico del trabajo subcontratado y del suministro de personal, Editorial Jurídica de Chile, Santiago, 2006.

PeN̂AILILlo, Daniel, Obligaciones. Teoría general y clasificaciones. La resolución por incumplimiento, Editorial Jurídica de Chile, Santiago, 2003, reimpresión de 2008.

PRADO, P., La subcontratación y el suministro en el Derecho civil, Editorial Legal Publishing, Santiago, 2009.

RAINOLTER, M. y GARCIA VIOR, A., Solidaridad laboral en la tercerización, Astrea, Buenos Aires, 2008.

Rosembaum, J. y CASTello, A., Subcontratación e intermediación laboral. Estudio de las leyes 18.099 y 18.251, Fundación de Cultura Universitaria, Montevideo, 2008.

SOMARriVA, Manuel, Tratado de las cauciones, Editorial Nascimento, Santiago, 1943. 